
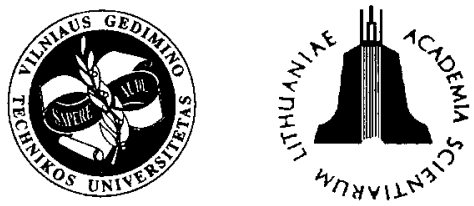

ISSN 1392-3730

JOURNAL OF CIVIL ENGINEERING AND MANAGEMENT

http:/www.vtu.lt/english/editions

2002, Vol VIII, No 4, 263--268

\title{
THE MODEL OF DETERMINING THE SENSITIVITY OF ELEMENTS OF MULTIPLE CRITERIA EVALUATION METHODS
}

\author{
Titas Dèjus \\ Vilnius Gediminas Technical University, Sauletekio al.11,LT-2040Vilnius, Lithuania.E-mail: titas.dejus@st.vtu.lt
}

Received 12 March 2001; accepted 10 June 2002

\begin{abstract}
Multipurpose version construction design under market conditions has no alternatives as only having formed sufficient quantity of variants to choose a rational, if not optimal, variant, which implemented will result in a priori known or enough close results. Performed calculations enable to state that the ideal point method is much more sensitive to changes of separate parameters and, applying the above-named method, it is necessary to take into account the fact that final result is effected by both decision matrix elements, indices importance parameters and also mathematical apparatus of the applied method. SAW method is sensitive to changes of separate parameters only, and sensitivity of mathematical apparatus may be defined as absolute ultimate insensitivity. The proposed model for determining methods of sensitivity to changes of separate parameters enables to increase the reliability of applied methods and expands opportunities for application of the theory of multipurpose evaluation methods in construction technology.
\end{abstract}

Keywords: construction management, decision-making, multicriteria evaluation method, sensitivity, test-matrix, modelling.

\section{Introduction}

In recent years the building construction variant design is applied more and more often. It means that construction is understood widely and encompasses the following stages: design of building architecture and structures, selection of building construction methods, construction technology and organisation design, determination of expediency of investments into new construction and reconstruction of existing buildings, determination of maintenance costs for buildings for the whole life cycle, etc.

Multipurpose variant construction design has no atternatives as only having formed a sufficient set of variants to select if not an optimal but a rational enough variant which, when realised, will result in a priori known or rather close results. In other case the probability that project realisation results will be unsatisfactory increases and this may mean both failure of a certain project and moral and financial bankruptcy of persons or their groups who have made false decisions.

The algorithm of rational variant determination is already known [1] and given in detail [2-9] for construction projects: having formed a decision-making matrix and having determined the importance of separate indices to compare, usually various, often mathematical, models enabling to form a row of variants (alternatives). In order to check the correctness of calculations it is recommended to use several multipurpose appraisal meth- ods and fix the final result to be an average value or apply Borda and Copeland methods [1].

The source [10] analyses the influence of subjective indices application for decision result and suggests the way for eliminating this influence by setting importance indices when multiplicative weighting method is used. The author offers to apply in the decision matrix the value of index instead of monosemantic index. This value is composed of two parts - constant and possible errors that may be both positive and negative. Applying analogous and indice importance describing model and solving the problem of rational alternative, a great scattered number of possible solutions is obtained and this, in the author's opinion, increases the reliability of calculation results.

The source [11] analyses opportunities of multipurpose appraisal in aviation industry. The authors offer to adapt a modified multiplicative weighting method: indices are divided into two groups - important for user and technical ones. Sets of indices to be compared are grouped according to generalised features thus reducing the set of indices to be compared to a rational number [11-13]. Significance is found from the scale of positive and negative values, then change of indices and their significance influence are analysed and called as sensitivity analysis.

Sensitivity analysis provides a means to determine the effect of the chosen objective weights and alterna- 
tive scores on the overall value of each alternative. It also provides the insight into where it would be beneficial to incorporate uncertainty. Sensitivity analysis was conducted on the objective weights and also on the evaluation measure scores.

The source [12] presents investigations related to multipurpose strategy appraisal in design of ecosystems. The article offers to use MOIRA software package generated on the basis of program of selecting rational variants that is based upon multiattribute value function method. The authors distinguish two phases of sensitivity analysis - main and supplementary. The main phase determines the change of alternatives upon change of indices values and their significance; it is very convenient for optimisation of a certain parameter. In the supplementary phase when unused information is accumulated, there is an opportunity to evaluate sensitivity indices (presented graphical interpretation). By this multiparameter analysis enables to check once more whether the chosen alternative is rational and make final decision about the strategy application.

The source [13] authors offer the structure of decision-making composed of eight segments. It shows that the sensitivity analysis plays an essential role in decision-making and enables to fix and limit sets of both alternatives and indices, their values and significance. The key step in decision analysis is a thorough sensitivity analysis, which indicates whether the rank order of management options changes under different assumptions. Sensitivity analysis should be done for different management objectives, different sets of hypotheses, or different probabilities on the range of parameter values. Sensitivity analysis will thereby identify the range of hypotheses, parameter values, or objectives over which the rank order of management options remains unchanged.

When generalising the analysed information, it should be noted that a great attention is drawn to sensitivity analysis; however, this analysis is performed in the "inside" of multipurpose appraisal method.

Unfortunately, I failed to find the sources showing the influence of separate mathematical appraisal methods upon the final result - a row of construction projects variants priority, though, the problem of reliability is analysed.

This problem is partly considered in $[1,4,13,14$, 15]. However, their authors offer to adapt other multipurpose appraisal methods in order to increase the results reliability, though reliability of mathematical instruments is not specified.

Some works not related to the design of construction organisation but analysing aspects of multipurpose alternatives valuation in another activity sphere do not offer formal mathematical methods. However, the following is to be emphasised: methods of data collection, grouping of indices according to structures and schemes [16] and influence of subjective factors in multipurpose alternatives valuation are stressed [17].
From another standpoint the situation may be justified as problems not considered in theoretical aspects and as a result of a long application of multipurpose construction variants appraisal methods and practical calculations.

The article offers to analyse the reliability of widelyspread in construction organisation design method - the SAW method and rarely applied the ideal point method through influence of segments (elements) values upon final result, ie to determine sensitivity of method, and the elements in analysis are both elements of decision matrix and significance of separate indices being actually the variables in all multipurpose appraisal models.

\section{The effect of the significance of method elements on determining priority series}

The algorithm of the multicriteria evaluation of construction projects can be divided into the following basic stages influencing the values of elements of a mathematical model:

- determination of the number of alternatives and indexes;

- determination of the values of elements of a decision-making matrix;

- determination of the values of index significance;

- determination of the preferred direction of changes in the indexes compared.

The indicated elements of each stage will be used just for determining their effect on the final result. This is done by two stages. At the first stage, the effect of change in an element is determined by changing its value, whilst at the second stage different combinations are formed by changing the values of two or several elements, thus determining the effect of a set of elements.

\subsection{Determination of sensitivity in SAW method}

This is one of the most frequently used methods of multicriteria evaluation of variants, not limited to construction, which is sometimes [2] called a simple method of an additive significance determination. The author is of opinion that the popularity of this method among construction specialists is determined by the fact that the analytical expression of its mathematical model is simple and that the sequence of mathematical operations is easily understood.

Test matrices are formed in order to determine the effect of the model elements values on the final result. These matrices are analogous with the decision-making matrix in which the number of variants and indexes and their values are selected in such a way where application of its data enables to perform a sufficient number of calculations and the results obtained enable to find out the effect of both the individual elements and their combinations in the course of determining the series of variant priority. Element values of the SAW1 test matrix are presented in Table 1. 
Table 1. Element values of the SAW1 test matrix

\begin{tabular}{|l|l|l|}
\hline Alternatives $\backslash$ Indexes & $\mathrm{R} 1$ & $\mathrm{R} 2$ \\
\hline $\mathrm{A} 1$ & 1.00 & 1.00 \\
\hline $\mathrm{A} 2$ & 1.01 & 1,01 \\
\hline $\mathrm{A} 3$ & 1,02 & 1.02 \\
\hline A4 & 1,05 & 1,05 \\
\hline A5 & 1.10 & 1.10 \\
\hline A6 & 1,20 & 1.20 \\
\hline A7 & 1,50 & 1,50 \\
\hline A8 & 2,00 & 2,00 \\
\hline A9 & 5,00 & 5,00 \\
\hline A10 & 10,00 & 10,00 \\
\hline A11 & 20,00 & 20,00 \\
\hline A12 & 50,00 & 50,00 \\
\hline A13 & 100,00 & 100,00 \\
\hline A14 & 200,00 & 200,00 \\
\hline
\end{tabular}

A test matrix of index significance is formed by analogy. However, when creating such a matrix one should take into consideration the fact that condition (1) must be satisfied while applying the SAW method and

$$
\sum_{j=1}^{n} W_{j}=1,
$$

determining the significance of indexes. The SAW1 test matrix features two indexes of each alternative, thus the significance values in the index significance test matrixes are also described for two indexes. Values of elements of a test matrix of an index significance are presented in Table 2.

It is proposed to determine by stages the effect of individual elements of the matrix upon the results of calculation.

At the first stage researchers determine whether the selected number of alternatives and numerical values of elements of the decision-making matrix have any effect upon the results.

Table 2. Values of elements of the SAW 10 test matrix of index significance

\begin{tabular}{|l|l|l|}
\hline Altern. \Significances & $\mathrm{rl}$ & $\mathrm{r} 2$ \\
\hline $\mathrm{q} 1$ & 0.01 & 0,99 \\
\hline $\mathrm{q} 2$ & 0.02 & 0,98 \\
\hline $\mathrm{q} 3$ & 0,05 & 0,95 \\
\hline $\mathrm{q} 4$ & 0,1 & 0,9 \\
\hline $\mathrm{q} 5$ & 0,2 & 0,8 \\
\hline $\mathrm{q} 6$ & 0.3 & 0,7 \\
\hline $\mathrm{q} 7$ & 0,4 & 0,6 \\
\hline $\mathrm{q} 8$ & 0,5 & 0,5 \\
\hline $\mathrm{q} 9$ & $-0,4$ & 0,6 \\
\hline $\mathrm{q} 10$ & $-0,4$ & $-0,6$ \\
\hline $\mathrm{q} 11$ & 0,2 & -0.8 \\
\hline $\mathrm{q} 12$ & 0,45 & 0,55 \\
\hline
\end{tabular}

Here, $r 1$ and $r 2$ represent significances of the respective indexes.
A summary test matrix is formed for this purpose from any variation of the SAW 1 test matrix and SAW 10 test matrix of index significance, ie without analysing any effects of significance. The codes and calculation results of the SAW101 summary test matrix are presented in Table 3.

Table 3. Codes and calculation results of the SAW101 summary test matrix

\begin{tabular}{|l|l|l|l|l|l|}
\hline & Codes & $\mathrm{R} 1$ & $\mathrm{R} 2$ & $\mathrm{R} 3$ & $\mathrm{R} 4$ \\
\hline 1 & A1A2q8 & 0,9901 & 1,000 & & \\
\hline 2 & A1A1A2q8 & 0,990 & 0,990 & 1,000 & \\
\hline 3 & A1A2A2q8 & 0,990 & 1,000 & 1,000 & \\
\hline 4 & A1A1A1A2q8 & 0,990 & 0,990 & 0,990 & 1,00 \\
\hline 5 & A1A1A2A2q8 & 0,990 & 0,990 & 1,000 & 1,00 \\
\hline 6 & A1A2A2A2q8 & 0,990 & 1,000 & 1,000 & 1,00 \\
\hline
\end{tabular}

Not a single alternative has changed its efficiency after six calculation cycles by changing the number of alternatives. This allows to draw an absolutely logical conclusion that in case of using the SAW method the final result of calculation is absolutely non-sensitive to the changes in the number of alternatives.

A summary test matrix is formed in order to determine the extent of sensitivity of calculation results by the changes in the values of elements of the decisionmaking matrix. It has been determined through comparison of the calculated indexes that the changes in the test matrix values calculated from the SAW1 test matrix correspond absolutely to the changes in the efficiency of alternatives.

Further, all relative values remained unchanged upon the modification of the desired direction of changes in both the indexes (maximisation of the compared indexes was replaced with minimisation). This allows to draw a conclusion that while using the SAW method the efficiencies of alternatives are not sensitive to the values of index significances or to the modification of the desired direction of changes in the index.

At the second stage, which begins only upon determining the fact that the values of all variables of the applied method, except for the significance of indexes, have no influence on the alternatives efficiency using the test matrix calculation method; the extent of changes in the final result is determined after changing the significances of indexes.

It is obvious from the calculations performed that under such values of a test matrix which are specified in Table 1 the efficiency of alternatives is changing and depends not on the significance value given to a specific index but on the ratio of the values of the compared indexes. Under the same ratio of the compared indexes the result will differ to the same extent as the values of specific indexes, and it is a constant value although the values of the priority matrix elements are different (eg $0,05+0,2=0,1+0,15=0,25$ ). Under such results of calculation a conclusion is drawn that the 
significances of alternatives in case of alternatives with the same index values have no influence on the final result.

Upon further calculations a SAW202 summary verification matrix is formed whereof calculable alternatives' codes and calculation results are presented in Table 4.

Table 4. Codes and calculation results of the SAW202 summary test matrix

\begin{tabular}{|l|l|l|l|l|l|}
\hline & Codes & $\mathrm{R} 1$ & $\mathrm{R} 2$ & $\mathrm{~K} 1$ & $\mathrm{~K} 2$ \\
\hline 1 & A1A2q21 & 0,6125 & 0,6118 & 0,13 & 0,111 \\
\hline 2 & A1A2q22 & 0,7300 & 0,6062 & 0,120 & 0,116 \\
\hline 3 & A1A2q23 & 0,75 & 0,584 & 0,1 & 0,133 \\
\hline 4 & A1A2q24 & 0,84 & 0,484 & 0,01 & 0,213 \\
\hline 5 & A1A2q25 & 0,845 & 0,4784 & 0,005 & 0,218 \\
\hline 6 & A4A5q26 & 0,7105 & 0,8283 & 0,065 & 0,128 \\
\hline 7 & A4A5q27 & 0,7777 & 0,771 & 0,033 & 0,171 \\
\hline 8 & A4A5q28 & 0,8315 & 0,7252 & 0,007 & 0,205 \\
\hline 9 & A4A5q29 & 0,8383 & 0,7195 & 0,003 & 0,21 \\
\hline 10 & A4A5-q29 & 0,7195 & 0,8383 & 0,21 & 0,003 \\
\hline
\end{tabular}

Here, $\mathrm{K} 1$ and $\mathrm{K} 2$ represent partial significances of the first and second modified indexes, respectively.

While the significance of the first index is decreasing from 0,25 to 0,01 , its partial significance is also proportionally decreasing from 0,13 to 0,005 . At the same time the efficiency of the first alternative is growing because this process is influenced by the changes in the significance (from 0,25 to 0,49$)$ and value $(9,0>4,0)$ of the second index.

In no single case it has been determined from the data submitted and upon calculations of randomly formed decision-making matrices (over 250 cases) that the values of index significances had any influence, except for the stipulated one, on the final calculation results, ie the SAW method is absolutely non-sensitive to the nominal values of significances. This means that when this method is used no limitations should be applied to the values of both the elements and significances of a decision-making matrix.

\subsection{Determination of sensitivity when using the ideal point method}

The essence of this method $[1,2,3]$ consists in formation of a generalized criterion on the basis of the deviation of the compared variants from the so-called ideal point that consists of the indexes of the best variants. In this case the $\mathrm{K}_{\mathrm{BIT}}$ criterion is applicable.

$$
K_{B I T_{i}}=\frac{L_{i}^{-}}{L_{i}^{+}+L_{i}} ; \forall_{i i}=1, \bar{m}
$$

$$
K_{B I T_{i}}=\left(\begin{array}{l}
1, \text { if } a_{i}=a^{+} ; \\
0, \text { if } a_{i}=a^{-} .
\end{array}\right.
$$

The influence of the values of elements and significances of the decision-making matrix on the final result is determined by the same methods as in the case of analysing variables of the SAW methods. Yet, one should take into consideration the fact that while calculating by the ideal point methods the sum of significances shall not be limited by any value. Thus, one should form a TOP1 test matrix and TOP10 test matrix of index significances, the values of which are presented in Tables 5 and 6.

Table 5. Values of elements of the TOP1 test matrix

\begin{tabular}{|l|l|l|}
\hline Altern. $\backslash$ Indexes & $\mathrm{R} 1$ & $\mathrm{R} 2$ \\
\hline A1 & 0,1 & 9,0 \\
\hline A2 & 0,2 & 4,0 \\
\hline A10 & 0,1 & 0,2 \\
\hline A12 & 10,0 & 20,0 \\
\hline
\end{tabular}

Table 6. Values of elements of the TOP10 test matrix of index significances

\begin{tabular}{|l|l|l|}
\hline Altern.\Significances & $\mathrm{r} 1$ & $\mathrm{r} 2$ \\
\hline $\mathrm{q} 1$ & 0,25 & 0,25 \\
\hline $\mathrm{q} 2$ & 1,0 & 1,0 \\
\hline $\mathrm{q} 3$ & 1,0 & 100,0 \\
\hline $\mathrm{q} 4$ & 2,0 & 200,0 \\
\hline $\mathrm{q} 9$ & 1,0 & 3,0 \\
\hline $\mathrm{q} 11$ & 100,0 & 300,0 \\
\hline $\mathrm{q} 12$ & 1,0 & 1,5 \\
\hline $\mathrm{q} 13$ & 1,0 & 10,0 \\
\hline $\mathrm{q} 14$ & 1,0 & 50,0 \\
\hline
\end{tabular}

Calculation results are presented in Table 7.

The calculations allow to maintain that when applying this method:

- under the same significances of indexes their values have no influence on the calculation results in cases of both minimising and maximising the indexes;

- under the variable values of index significances the final results change in proportion to the changes in the significances, and changes in the ratio of efficiencies of alternatives correspond to the number of changes in the index significances;

- under formation of the decision-making matrix from a different number of alternatives and even without changing the values of indexes of an alternative the significances of variants are different although the series of priorities remain unchanged;

- the significance of an alternative depends on the ratio of index values and not on the numerical values of indexes;

- under changes to the number of compared indexes 
Table 7. Codes and calculation results of the TOP101 summary test matrix

\begin{tabular}{|l|l|l|l|}
\hline Codes & $\mathrm{R} 1$ & $\mathrm{R} 2$ & $\mathrm{R} 1 / \mathrm{R} 2$ \\
\hline A1A2q1 & 0,531658 & 0,468342 & $\mathbf{1 , 1 3 5 1 9}$ \\
\hline A1A2q2 & 0,531658 & 0,468342 & $\mathbf{1 , 1 3 5 1 9}$ \\
\hline A1A2-q2 & 0,468342 & 0,531658 & \\
\hline A1A2q3 & 0,991268 & 0,008732 & $\mathbf{1 1 3 , 5 2 1 3}$ \\
\hline A1A2q4 & 0,991268 & 0,008732 & $\mathbf{1 1 3 , 5 2 1 3}$ \\
\hline A1A2A1q4 & 0,989224 & 0,010776 & $\mathbf{9 1 , 7 9 8 8}$ \\
\hline A1A2A2q4 & 0,992963 & 0,007037 & $\mathbf{1 4 1 , 1 0 6}$ \\
\hline A10A2q2 & $\mathbf{0 , 0}$ & $\mathbf{1 , 0}$ & \\
\hline A10A12q2 & $\mathbf{0 , 0}$ & $\mathbf{1 , 0}$ & \\
\hline A1A2q9 & 0,773015 & 0,226985 & $\mathbf{3 , 4 0 5 5 7 7 4}$ \\
\hline A1A2R2q9 & 0,828067 & 0,171933 & $\mathbf{4 , 8 1 6 2 1 9 7}$ \\
\hline A1A2R1q9 & 0,518522 & 0,481475 & $\mathbf{1 , 0 7 6 9 4 4 8}$ \\
\hline A1A2R1R1q9 & 0,438610 & 0,561390 & $\mathbf{1 , 2 7 9 9 2 9 7}$ \\
\hline A1A2Rsq9 & 0,649585 & 0,350415 & \\
\hline A1A2q11 & 0,773015 & 0,226985 & 3,4055774 \\
\hline A1A2q2 & 0,531658 & 0,468342 & $\mathbf{1 , 1 3 5 1 9 1 8}$ \\
\hline A1A2q12 & 0,630012 & 0,369988 & $\mathbf{1 , 7 0 2 7 9 0 3}$ \\
\hline A1A2q9 & 0,773015 & 0,226985 & $\mathbf{3 , 4 0 5 5 7 7 4}$ \\
\hline A1A2q13 & 0,919041 & 0,080959 & $\mathbf{1 1 , 3 5 3 1 6 6}$ \\
\hline A1A2q14 & 0,982687 & 0,017313 & $\mathbf{5 6 , 7 6 0 0 6 4}$ \\
\hline
\end{tabular}

not only the significances of alternatives change but the series of priorities as well.

These arguments are applicable to the system parameters of element modification and determination of relations. Several variants were also calculated with regard to the impact of changes in random (non-system) elements upon the final results, which variants would not allow to uniquely determine the correlation between the changes in the results and changes in the elements.

In accordance with the above-mentioned and upon completion of a series of verification calculations by using real data of conctruction projecting it is possible to draw a conclusion that the sensitivity of index significances of the method under investigation is perceptibly greater as compared with the SAW method of calculating the rational variants of a construction technology or preparation.

\section{Algorithm of determining the parameters' effect}

The comparative analysis conducted only with regard to the two methods is not sufficient for wide generalizations and strictly defined conclusions that could be applied to the multicriteria evaluation of construction variants performed by any methods. However, the accumulated data and the above-mentioned results of the research allow to offer the generalized algorithm of the sensitivity determination model whereof flowsheet is presented in Fig.

While commenting the offered algorithm of determining sensitivity of methods of the multicriteria evalu-

Determination of elements of multicriteria evaluation methods which elements have effect on calculation results

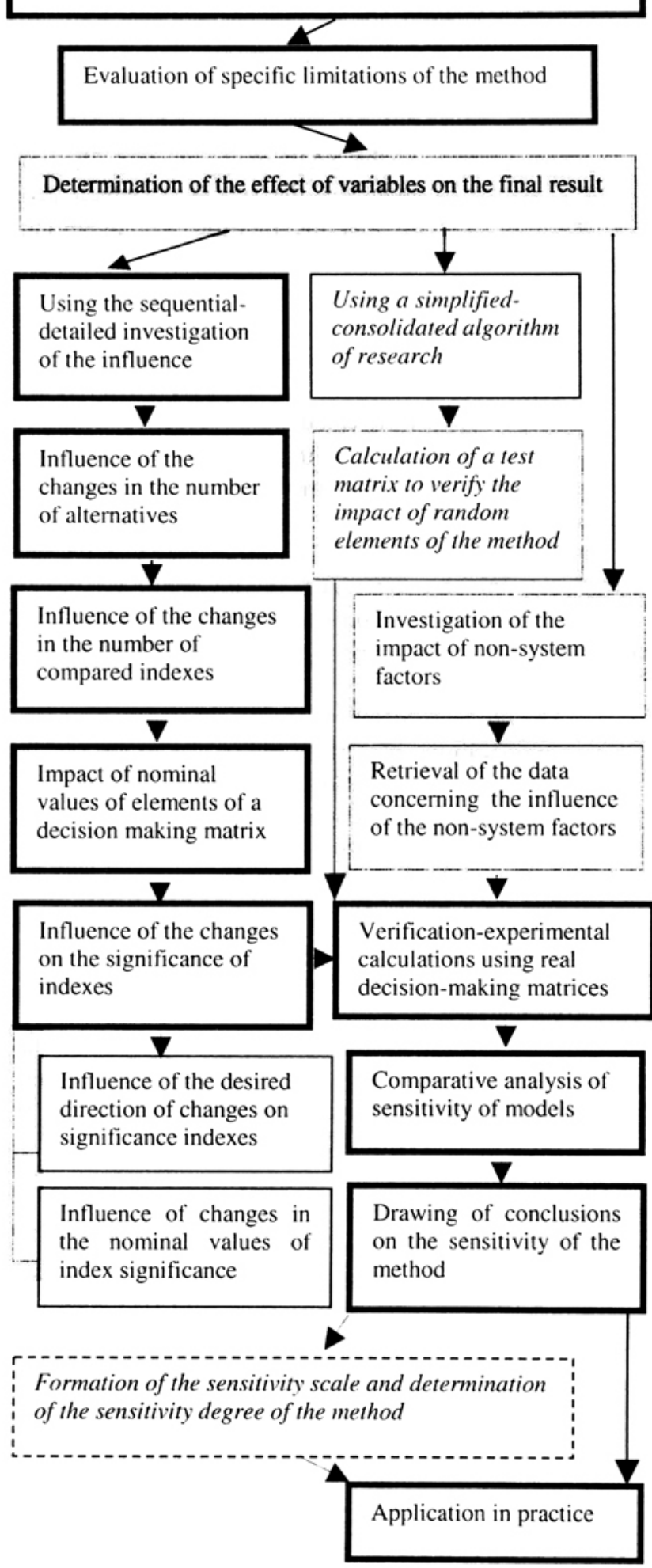

I he tlowsheet of the algorthm of determining the sensitivity of multicriteria evaluation methods 
ation, it is necessary to point out that the main path of the algorithm (marked with the bold box) should be such a branch of the algorithm in which the sensitivity is determined by applying the sequential detailed investigation because only in this case a method is analysed in sufficient detail, which fact creates preconditions for avoiding any error.

\section{Conclusions}

1. An analysis of the SAW multicriteria evaluation method has been conducted, the results of which give the basis to maintain that the modification of certain parameters of the above-mentioned method has no influence on the final results of calculation. This means that only the significances of indexes have a fully examined impact as regards the determination of efficiency of an alternative.

2. The results of the calculation performed by using the ideal point method show that this method is perceptibly more sensitive to the modification of certain parameters. When applying the above-mentioned method in practice one should know that the final result is affected not only by the values of elements and index significances of a decision-making matrix but by other parameters as well (eg the size of the decision-making matrix).

3. The model of determining the sensitivity of methods to modifications of certain individual parameters is offered; it allows to increase the reliability of the methods used and extends the possibilities of applying the theory of the multicriteria evaluation of the construction technology and management projects.

4. The algorithm of determining the sensitivity of multicriteria evaluation methods is presented as an integrity of the two alternatives that are different by the accuracy of results and amounts of the work performed.

5. The landmarks of further development of the problem have been stipulated, ie creation of the sensibility scale and determination of the sensitivity degree of the methods under analysis.

\section{References}

1. Ching-Lai Hwang, Kwang-sun Yoon. Multiple Attribute Decision-making Methods and Applications. Berlin, Heidelberg, New York: Springer - Verlag, 1981. $260 \mathrm{~S}$.

2. Zavadskas, E.; Vaigauskas, E. Application of decisionmaking theory methods in preparation of construction (Sprendimų priemimu teorijos metodụ taikymas ruošiant statybą). Vilnius: VISI, 1985. $64 \mathrm{p}$ (in Lithuanian).

3. Zavadskas, E. K.; Kaklauskas, A. Systemotechnical appraisal of buildings. (Pastatu sistemotechninis ivvertinimas). Vilnius: Technika, 1996. 279 p (in Lithuanian)
4. Zavadskas, E. K.; Simanauskas, L.; Kaklauskas, A. Decision support system in civil engineering (Sprendimu paramos sistemos statyboje). Vilnius: Technika, 1998. $235 \mathrm{p}$ (in Lithuanian).

5. Mitkus, S.; Dejus, T. Quality investigation methods (Kokybiniai tyrimo metodai). V.: Vailinta, 1999. 44 p (in Lithuanian).

6. Zavadskas, E. K.; Ustinovičius, L.; Turskis, Z.; Peldschus, F; Messing, D. LEVI 3.0 - Multiple criteria evaluation program for construction solutions. J. of Civil Engineering and Management, Vol VIII, No 3. Vilnius: Technika, 2002, p 184-191.

7. Malinauskas, P.; Petrašenko, T. Multiple criteria analysis of dwelling facilities maintenance. Civil Engineering (Statyba), VII t., Nr. 2. Vilnius: Technika, 2001, p 138 147 (in Lithuanian).

8. Dejjus, T.; Mitkus, $S$. Evaluation model of dry mixes for plasterboards. Civil Engineering (Statyba), VII t., Nr. 3. Vilnius: Technika, 2001, p 224-230 (in Lithuanian).

9. Lunkevičius, S.; Ustinovičius, L.; Zavadskas, E. K. Ranking efficiency of rural property investment projects using multicriteria decision methods. Civil Engineering (Statyba), VII t., Nr. 3. Vilnius: Technika, 2001, p 238-246 (in Lithuanian).

10. Kwangsun Yoon. The Propagation of Errors in Multipleattribute Decision Analysis: A Practical Approach. Journal of the Operational Research Society, Vol 40, No 7, 1989, p 681-686.

11. Gwen Delano; Gregory S. Parnell; Charles Smith; Matt Vance. Quality function deployment and decision analysis. International Journal of Operations \& Production Management, Vol 20 No 5, 2000, p 591-609.

12. Mateos, A.; Rios-Insua, S.; Gallego, E. Postoptimal analysis in a multi-attribute decision model for restoring contaminated aquatic ecosystems. Journal of the Operational Research Society (2001) 52, p 727-738.

13. Randall M. Peterman and Judith L. Anderson. Decision Analysis: A Method for Taking Uncertainties into Account in Risk-Based Decision Making, Human and Ecological Risk Assessment: Vol 5 No 2, p 231-244 (1999).

14. Peldschus, F.; Zavadskas, E. K. Matrix games in construction technology and management (Matriciniai lošimai statybos technologijoje ir vadyboje). Vilnius: Technika, 1997. $134 \mathrm{p}$ (in Lithuanian).

15. Seo, F. Organizational Aspects of Multicriteria Decisionmaking. In: Lecture Notes in Economics and Mathematical System. Berlin, Heidelberg. New York, 1981, p 363379.

16. Canez, L. E.; Platts, K. W. and Probert, D. R. A framework for make-or-buy decision. International Journal of Operations \& Production Management, Vol 20 No 11, 2000, p 1313-1330.

17. Samuel M. Natale, Anthony F. Libertella and Brian M. Rothschild. Decision-making process: the key to quality decision. American Journal of Management Development Vol 1, No 4, 1995, p 5-8. 